\title{
Monte Carlo Characterization of a Pulsed Laser-Wakefield Driven Monochromatic X-Ray Source
}

\author{
S. D. Clarke, S. A. Pozzi, IEEE Member, N. Cunningham, S. Banerjee, D. Umstadter
}

\begin{abstract}
The Diocles laser at the University of Nebraska presents the possibility of producing a tunable, monochromatic $\mathrm{X}$-ray source that has obvious applications in nuclear material detection. The pulsed and directional nature of this X-ray source makes traditional spectroscopy techniques for characterizing this source challenging. The large number of $X$-rays arriving at the detector in a short period of time would result in a high degree of pulse pileup, making the individual $X$-ray energy indistinguishable. In the technique presented in this paper, a series of attenuator materials will be placed in the path of the $X$ rays and the integral detector response will be measured. A series of detector response measurements with different attenuators will allow determination of the incident $X$-ray energy by using unfolding techniques.
\end{abstract}

\section{INTRODUCTION}

THE Diocles laser facility at the University of Nebraska1 Lincoln (UNL) is a 100-TW, 30-fs pulsed Ti:sapphire laser system. Diocles is routinely used to accelerate electron beams by means of laser-wakefield acceleration, which exhibit high energy (up to $400 \mathrm{MeV}$ ), high beam charge $(0.1 \mathrm{nC}$ ) and narrow energy width $(10 \%)[1,2]$. Table I lists the other properties of the Diocles laser. These electrons may be scattered off of laser light from the same laser system, producing monochromatic X-rays with energy and spectral width that are directly related to those of the electron beam [3, 4]. This novel approach presents the possibility of producing a tunable, monochromatic X-ray source that has promising applications in nuclear material detection.

The objective of this work is to demonstrate a methodology for the characterization of these experimentally generated Xrays. The pulsed and directional nature of the X-ray source under development at UNL makes traditional spectroscopy techniques challenging. Unless some means is used to reduce

Manuscript submitted on November 13, 2009.

S. D. Clarke is with the Department of Nuclear Engineering and Radiological Sciences of the University of Michigan, Ann Arbor, MI 48109 USA (tel: 734-615-7830, e-mail: clarkesd@umich.edu).

S. A. Pozzi is with the Department of Nuclear Engineering and Radiological Sciences of the University of Michigan, Ann Arbor, MI 48109 USA (tel: 734-615-4970, e-mail: pozzisa@umich.edu).

N. Cunningham is with the Physics and Astronomy Department of the University of Nebraska, Lincoln, NE 68588 USA (e-mail: ncunningham2@unl.edu).

S. Banerjee is with the Physics and Astronomy Department of the University of Nebraska, Lincoln, NE 68588 USA (e-mail: sbanerjee2@unl.edu).

D. Umstadter is with the Physics and Astronomy Department of the University of Nebraska, Lincoln, NE 68588 USA (tel: 402-472-8115, e-mail: dpu@ unlserve.unl.edu). the large number of X-rays arriving at the detector in a short period of time, a high degree of pulse pileup would result, making the individual X-ray energy indistinguishable [5]. For instance, one could place traditional gamma at a large distance away from the source at an off-axis angle to reduce the number of detected photons. However, this would require a very large number of electron/laser shots to achieve the measurement statistics necessary for reliable spectroscopy.

\begin{tabular}{ll} 
TABLE I. PROPERTIES OF THE UNL DIOCLES LASER FACILITY \\
\hline Peak power & $140 \mathrm{TW}$ \\
Repetition rate & $10 \mathrm{~Hz}(0.1 \mathrm{~Hz})$ \\
Central wavelength & $805 \mathrm{~nm}$ \\
Pulse duration & $<30 \mathrm{fs}$ \\
Pulse energy & $3.5 \mathrm{~J}$ (compressed) \\
Energy stability & \\
$\quad$ Short-term & $1.5 \% \mathrm{rms}$ \\
$\quad$ Medium $(1 \mathrm{hr})$ & $0.5 \% \mathrm{rms}, 2.5 \%$ \\
Long $(8 \mathrm{hr})$ & $0.8 \% \mathrm{rms}, 4.9 \%$ \\
Pointing stability $(1 \mathrm{~min})$ & $3.5 \mu \mathrm{rad}$ \\
Contrast & $3 \times 10^{-8}$ at $1 \mathrm{~ns}$ \\
Strehl ratio & 0.95 \\
Focusability & diffraction-limited \\
Maximum intensity & $10^{22} \mathrm{~W} / \mathrm{cm}^{2}(\mathrm{f} / 2)$ \\
\hline
\end{tabular}

\section{SOURCE CHARACTERIZATION METHODOLOGY}

In the technique described here, a series of attenuator materials will be placed in the path of the X-rays, and the integral detector response will be measured. The response of the detector to incoming photons may be described by,

$L(t, E)=R_{i}(t, E) \Phi(E)$

where $L(t, E)$ is the light output if the detector, $\Phi(E)$ is the incident photon spectrum, $t$ is the attenuator thickness, $E$ is the photon energy, and $R$ is called the detector response matrix for attenuator material $i$. If the detector response matrix is known for a various attenuators, the incident photon spectrum may be determined using spectral unfolding techniques.

\section{MCNP MODEL DESCRIPTION}

The experimental setup was modeled in MCNP5 [6]. The attenuators will be constructed out of aluminum, copper, stainless steel and lead in thicknesses of $1.0 \mathrm{~cm}$ up to $10.0 \mathrm{~cm}$. The attenuator will be placed in the beamline inside of the laser vacuum chamber with the detector located just outside. 
Fig. 1a shows an illustration of the setup. The detector is a $40 \times 40$ array of $\mathrm{CsI}(\mathrm{Tl})$ crystals, which has a high density and large light response (the crystals emit an average of 54 visible photons per $\mathrm{keV}$ of energy deposited). Each detector crystal is $1 \times 1 \times 20 \mathrm{~mm}^{3}$. A $0.2-\mathrm{mm}$ thick layer of an epoxy compound ( $1: 1$ epoxy: $\mathrm{TiO}_{2}$ ) exists between each detector crystal (the epoxy composition is approximated as $73 \% \mathrm{C}, 7 \% \mathrm{H}, 20 \% \mathrm{O}$ with $\rho=1.0 \mathrm{~g} / \mathrm{cm}^{3}$ ). An additional $1.6 \mathrm{~mm}$ of epoxy exists around the parameter of the detector array. A $1.0-\mathrm{mm}$ thick epoxy layer exists on one face of the array with the other face bare. This results in a total array size of $51 \times 51 \times 21 \mathrm{~mm}^{3}$. Fig. $1 \mathrm{~b}$ shows a detail of the CsI(Th) array face.

The range of parameters for the X-ray source were supplied by and are representative of the X-rays that are expected from the Diocles facility. The photon source should range from 0.5 to $3.0 \mathrm{MeV}$ with a Gaussian shape and a full-width-at-halfmaximum of approximately $20 \%$. The photons were modeled in a conical beam with a 0.0027 -radian angular spread. This range of beam energies and attenuator thicknesses will be used to generate response matrices for each attenuator material. The response matrix for a given attenuator is defined as the total light output of the detector array as a function of beam energy and attenuator thickness.

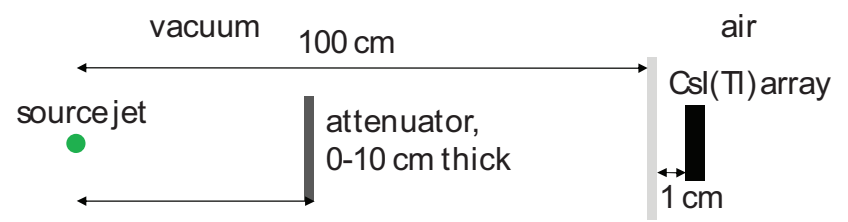

$40 \mathrm{~cm}$ (from source To attenuator exit)

glass, $5 \mathrm{~mm}$ thick

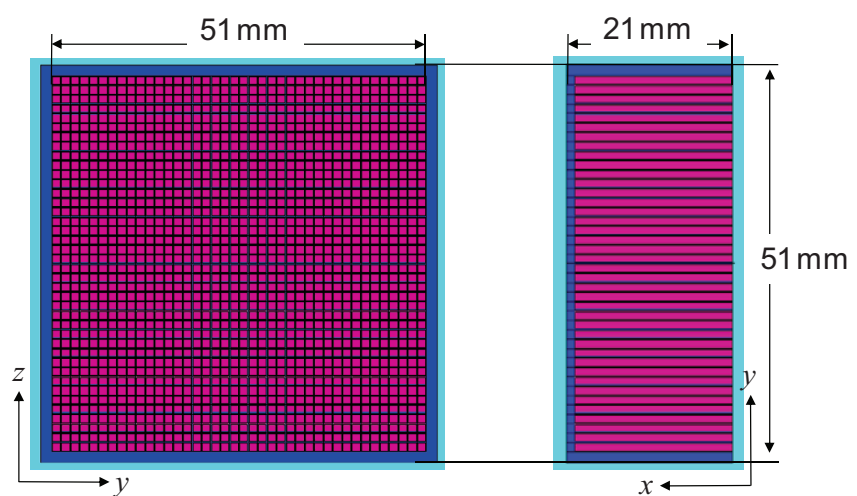

Fig. 1. MCNP5 model of the X-ray source characterization setup and a detailed view of the $\mathrm{CsI}(\mathrm{Th})$ detector array

\section{MCNP BEAM RESPONSE CHARACTERIZATION}

The spatial energy deposition in the CsI detector array has been characterized in the presence of various X-ray spectra. Fig. 2 shows the change in the $1.5-\mathrm{MeV}$ Gaussian source spectrum after passing through varying thicknesses of copper. As expected, the X-ray spectrum softens considerably as it passes through increasingly thick copper slabs. This behavior is unique to the X-ray source energy, the energy spread, as well as the thickness and material of the attenuator. Fig. 3 shows this behavior for all of the attenuator materials of interest.

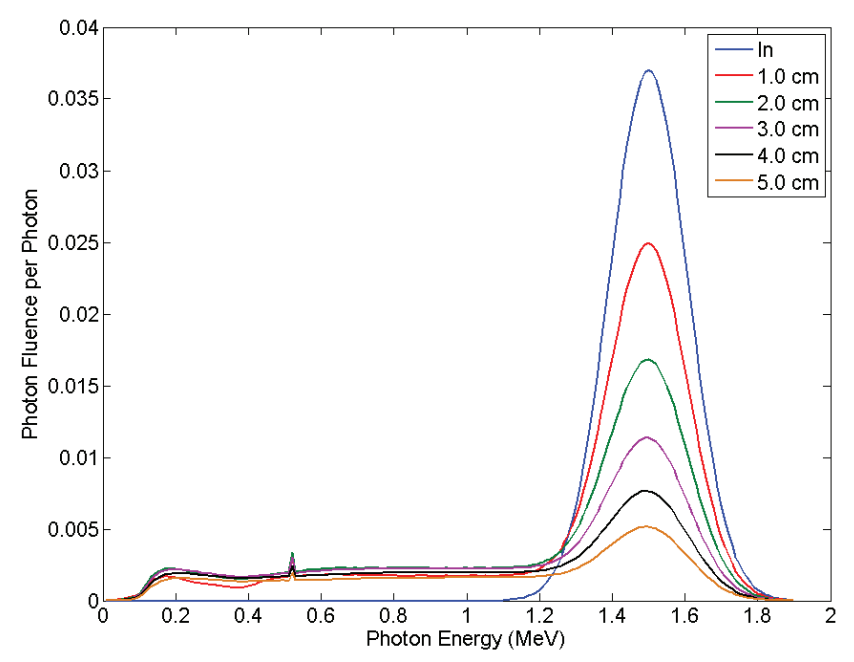

Fig. 2. Spectrum from a $1.5-\mathrm{MeV}$ photon beam passing through varying thicknesses of copper.

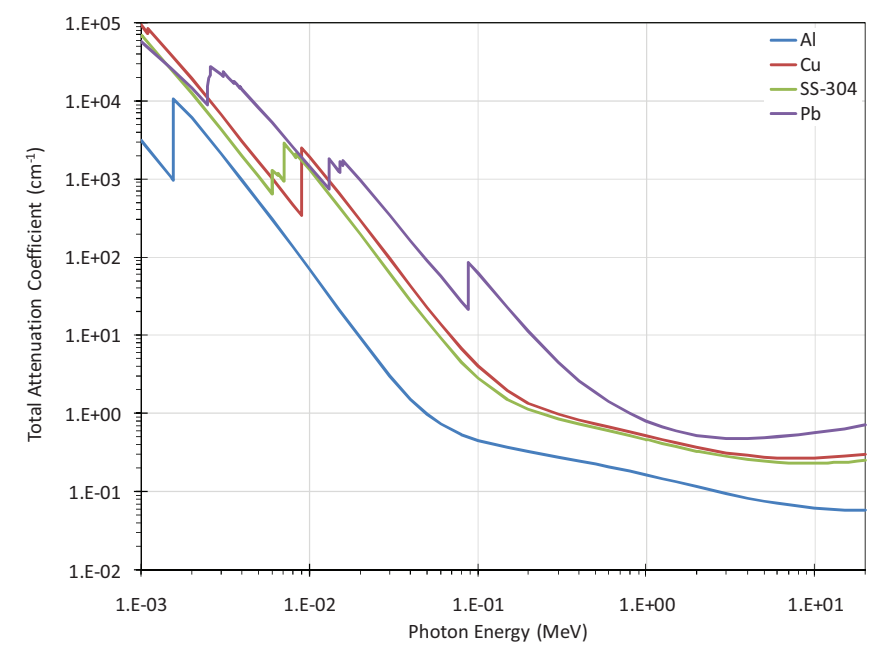

Fig. 3. Total X-ray attenuation coefficients for the attenuator materials on interest [7].

Fig. 4 shows the log relative energy distribution for a 1.5$\mathrm{MeV}$ photon beam passing through a $2.0-\mathrm{cm}$ thick copper attenuator; the statistical relative error is also shown. A large amount of energy is deposited in the central four pixels (about $80 \%$ of the total). This is due to the highly collimated nature of the beam. Similar results were obtained for each attenuator material, thickness, and beam energy. 

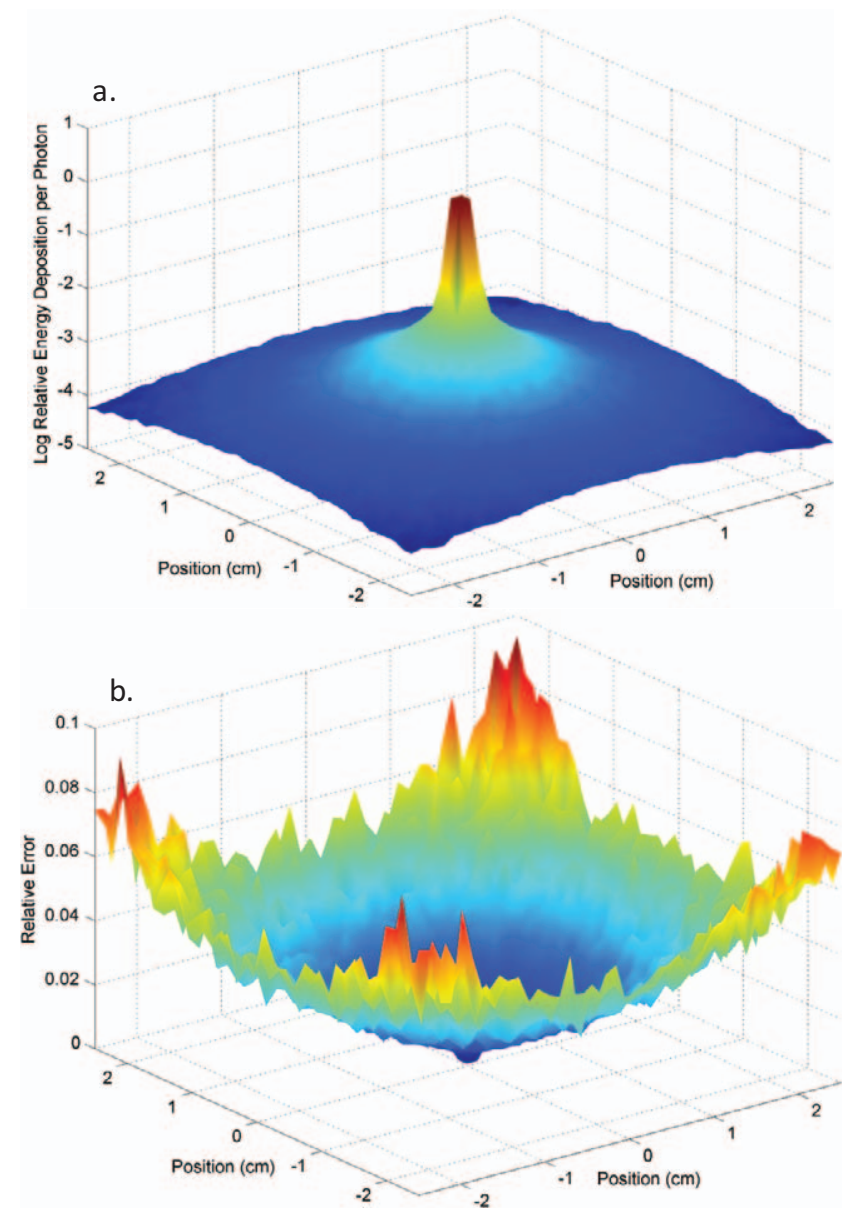

Fig. 4. $\log _{10}$ relative energy deposition in the CsI(Th) detector array from a $1.5-\mathrm{MeV}$ photon beam passing through a $2.0-\mathrm{cm}$ thick copper attenuator; the statistical relative error is also shown.

\section{A. Cross-Talk Analysis}

Some portion of the energy deposited in each pixel comes from photons that scatter from adjacent pixels: this is called the cross-talk contribution. Only photons which interact directly from the source are desirable for source characterization. Thus, it is important to quantify the crosstalk effect. The energy deposition in each detector pixel was flagged using the side surfaces of each pixel. This separates the contributions to the energy tally that come from particle that have passed through any side surface, effectively isolating the cross-talk response. Fig. 5 shows these results for a 1.5$\mathrm{MeV}$ beam passing through a $2-\mathrm{cm}$ thick copper attenuator. The cross-talk portion is clearly a very small fraction of the total signal. This can be more clearly seen in Fig. 6 which shows that total and cross-talk distributions along the detector centerline. In the central four pixels, the cross talk response is less than $1 \%$ of the total, while it is nearly $100 \%$ in the outer pixels. However, this contribution is three orders-ofmagnitude less than the central pixels. Therefore, cross-talk should not be a concern in these experiments.
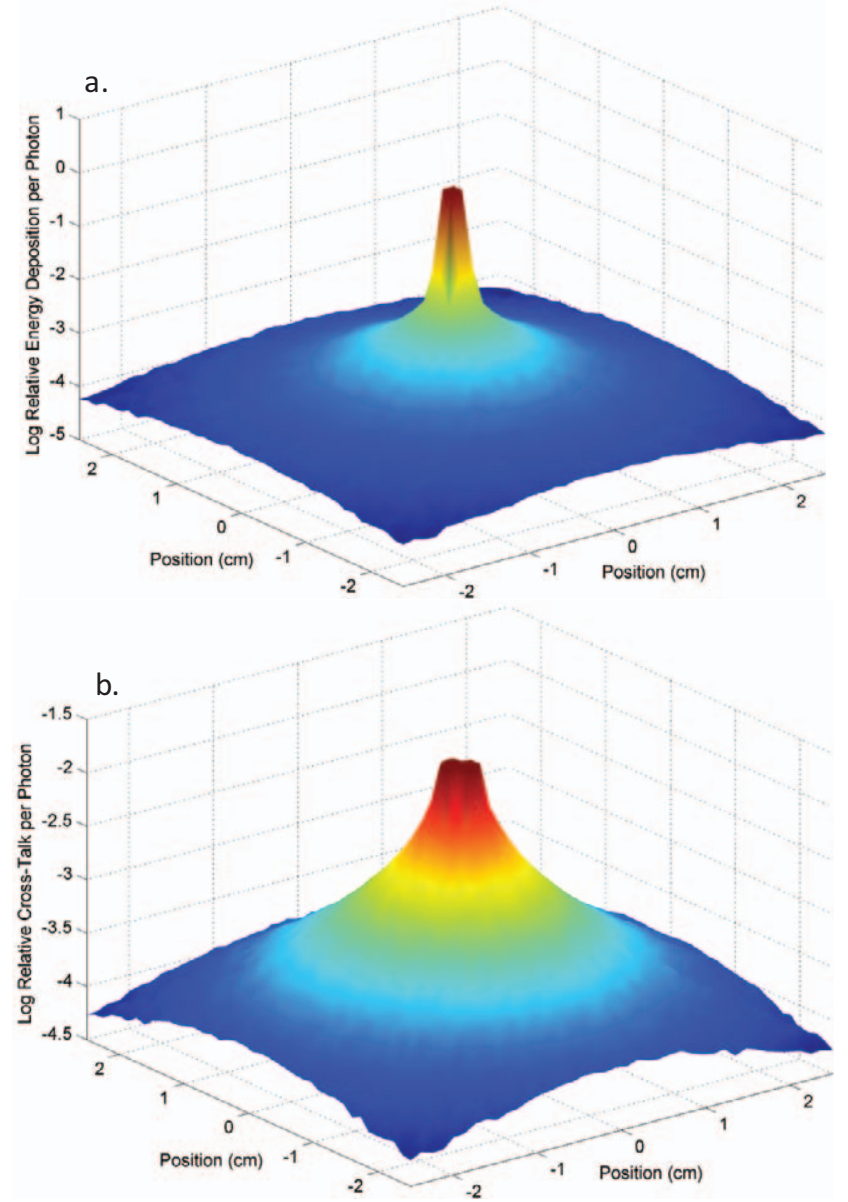

Fig. 5. $\log _{10}$ relative energy deposition in the CsI(Th) detector array from a $1.5-\mathrm{MeV}$ photon beam passing through a $2.0-\mathrm{cm}$ thick copper attenuator. The total response is shown in (a) and the cross-talk portion is shown in (b).

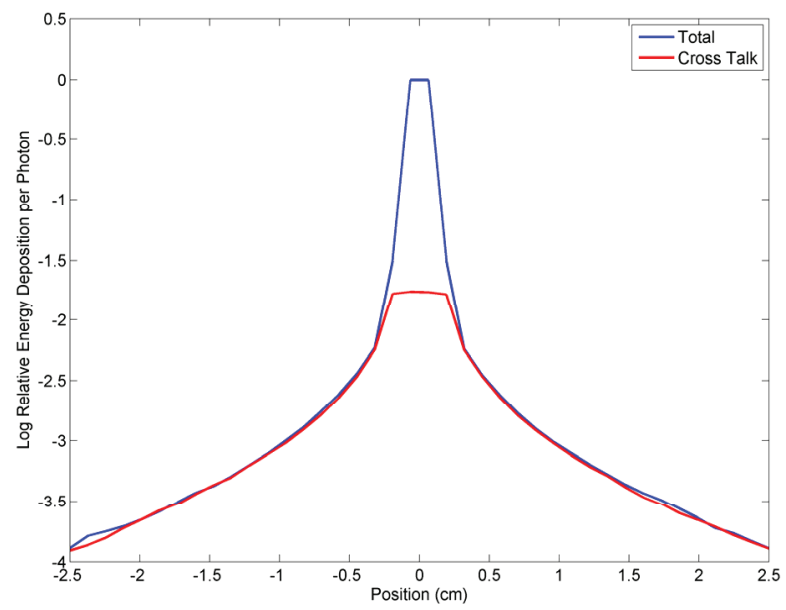

Fig. 6. $\log _{10}$ relative energy deposition along the centerline of the CsI(Th) detector array from a $1.5-\mathrm{MeV}$ photon beam passing through a $2.0-\mathrm{cm}$ thick copper attenuator. The total and cross-talk responses are shown. 

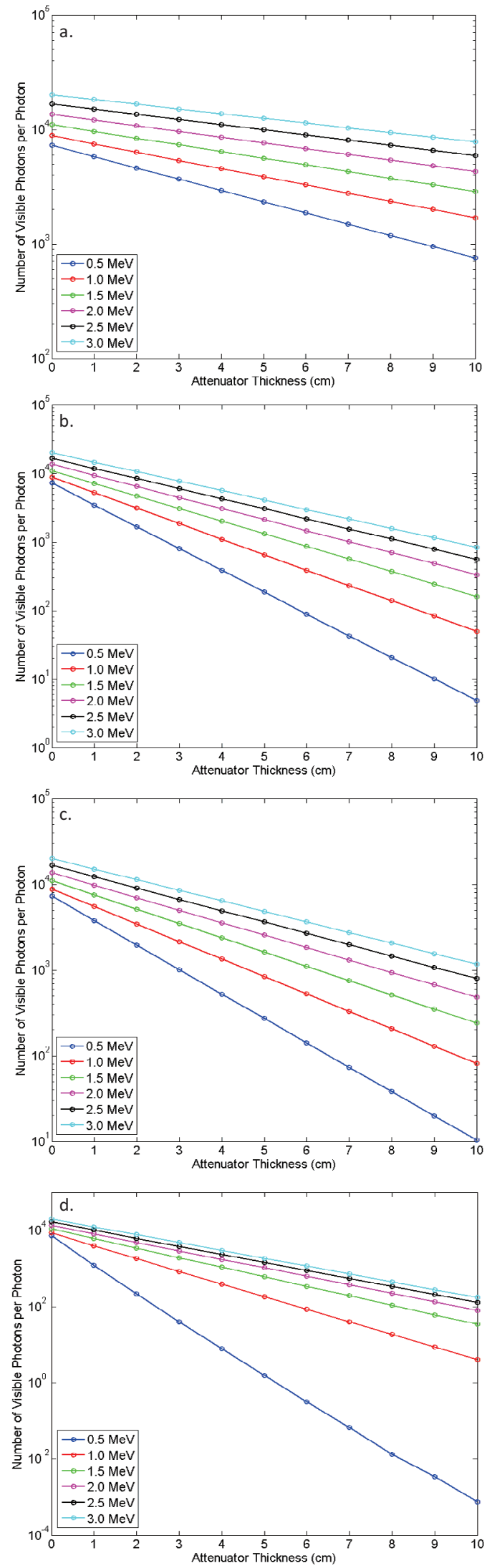

Fig. 7. Average total light emitted ate various photon source energies for aluminum (a), copper (b), stainless steel (c), and lead (d) attenuators of varying thickness.
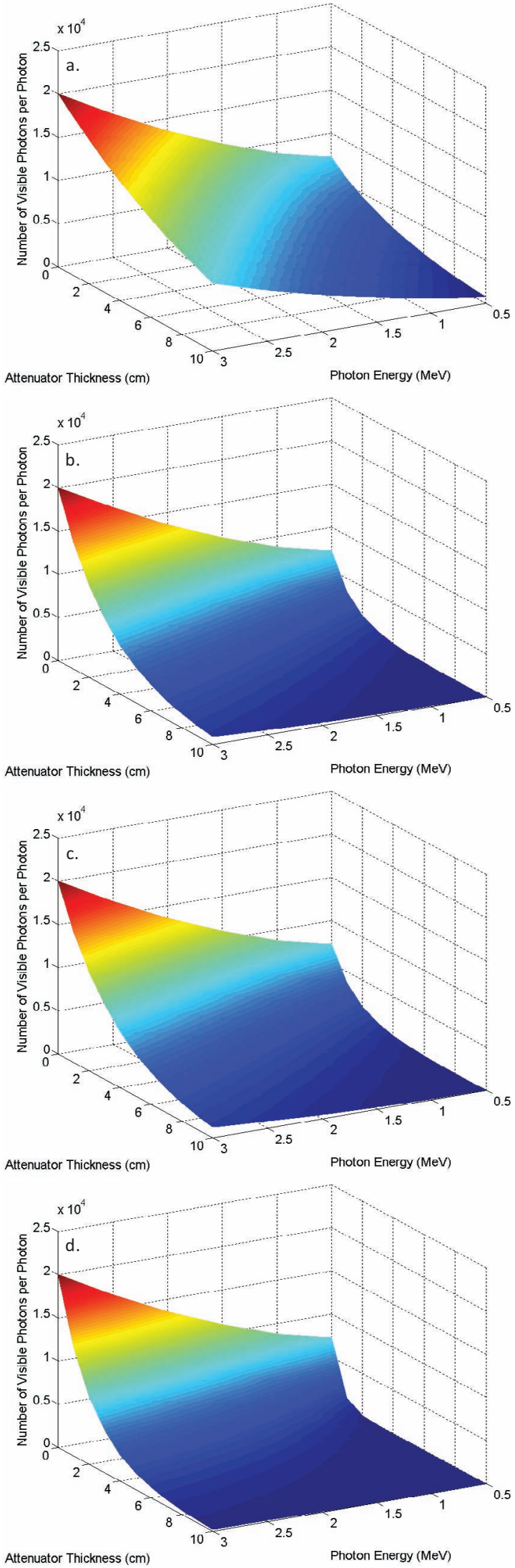

Fig. 8. General detector response matrices for aluminum (a), copper (b), stainless steel (c), and lead (d). 


\section{B. Response Matrix Calculation}

The light output from $\mathrm{CsI}(\mathrm{Tl})$ is known to be 54 visible photons per $\mathrm{keV}$ of energy deposited in the detector. Therefore, the average total light emitted from the detector may be computed directly from the MCNP volumetric energy deposition tally such as those results shown in Fig. 6. Each attenuator material was simulated in $1.0-\mathrm{cm}$ thickness increments with photons of energy ranging from $0.5-3.0$ $\mathrm{MeV}$ in $0.5 \mathrm{MeV}$ increments. At each energy, the FWHM was fixed to $20 \%$.

Fig. 7 shows the total average light output as a function of attenuator thickness at several incident photon energies for each attenuator material. The rate of the signal decrease with increasing attenuator thickness is a function of the material density and effective $Z$ as well as the incident photon energy.

When visualized as interpolated, three-dimensional surface, the results in Fig. 7 are seen as response matrices. Fig. 8 shows these results for each attenuator material. The lead attenuator exhibits the most dramatic response with respect to energy and thickness, while aluminum exhibits the least dramatic response. This is due to the fact that they have the most extreme values of density and atomic number. Copper and stainless steel show a similar response, due to having a similar density and atomic number.
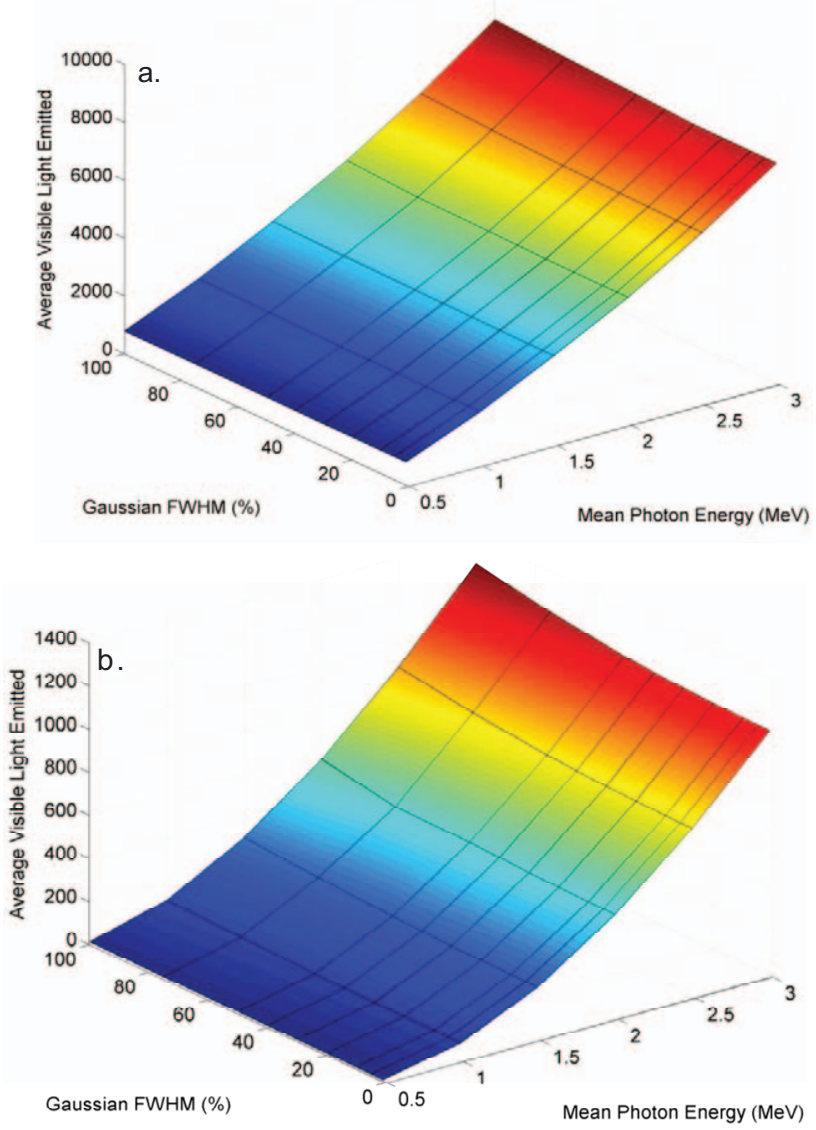

Fig. 9. Detailed detector response matrices for a 3.0- (a) and 9.0-cm (b) thick copper attenuators.
The behavior of the response matrix with respect to spectral width was also explored. Fig. 9 shows a detail of the copper response matrix at two specific thicknesses: 3.0 and $9.0 \mathrm{~cm}$. The change in light output with respect to a change in spectral width is small with respect to the change in source energy at both thicknesses. It may be possible to extract both source parameters (energy and spectral width) given consecutive, repeatable experimental shots (because there are two unknowns). The repeatability of consecutive shots will be assessed with measurement results provided by the University of Nebraska.

\section{V.SOURCE CHARACTERIZATION ALGORITHM}

An algorithm has been developed to determine the source energy from the simulated detector light output and the response matrices described in the previous section. The algorithm accepts the total light output, attenuator material and attenuator thickness and returns the source energy. The attenuator information determines the response matrix row from which the source energy is calculated. The algorithm performs a table-lookup operation based on linear interpolation.

A series of simple test cases were performed to test the performance if the identification algorithm. Five source energies were randomly selected within the response matrix domain $(0.5 \leq E \leq 3.0 \mathrm{MeV})$. A fixed, $20 \%$ FWHM spectral width was applied for each source energy. Each beam was transported through one of the four attenuator materials with a random thickness. The total light output was calculated and the source energy was computed using the appropriate response matrix. Table II summarizes these cases, and the identification results.

TABLE II. SUMMARY OF THE RESULTS FROM THE SOURCE IDENTIFICATION ALGORITHM TEST CASES. FOR EACH CASE, THE THICKNESS, PREDICTED ENERGY VALUE AND PERCENT DIFFERENCE RELATIVE TO THE TRUE VALUE ARE GIVEN.

\begin{tabular}{|c|c|c|c|c|c|}
\hline \multirow{2}{*}{$\begin{array}{c}\text { Test } \\
\text { Energy } \\
(\mathrm{MeV})\end{array}$} & \multicolumn{4}{|c|}{ Attenuator material } & \multirow{2}{*}{$\begin{array}{c}\text { Average } \\
\text { Predicted } \\
\text { Energy } \\
(\mathrm{MeV})\end{array}$} \\
\hline & $\mathrm{Cu}$ & $\mathrm{Pb}$ & SS & $\mathrm{Al}$ & \\
\hline 0.7 & $\begin{array}{c}3.0 \\
0.6862 \\
(-1.98 \%)\end{array}$ & $\begin{array}{c}1.0 \\
0.7235 \\
(-3.36 \%)\end{array}$ & $\begin{array}{c}7.0 \\
0.6568 \\
(-6.17 \%)\end{array}$ & $\begin{array}{c}3.0 \\
0.6782 \\
(-3.00 \%)\end{array}$ & $\begin{array}{c}0.6862 \\
(-1.98 \%)\end{array}$ \\
\hline 1.3 & $\begin{array}{c}4.0 \\
1.2989 \\
(-0.08 \%)\end{array}$ & $\begin{array}{c}3.0 \\
1.3060 \\
(-0.46 \%)\end{array}$ & $\begin{array}{c}4.0 \\
1.2905 \\
(-0.73 \%)\end{array}$ & $\begin{array}{c}6.0 \\
1.2930 \\
(-0.54 \%)\end{array}$ & $\begin{array}{c}1.2971 \\
(-0.22 \%)\end{array}$ \\
\hline 1.8 & $\begin{array}{c}8.0 \\
1.7845 \\
(-0.86 \%)\end{array}$ & $\begin{array}{c}4.0 \\
1.8038 \\
(-0.21 \%)\end{array}$ & $\begin{array}{c}6.0 \\
1.7888 \\
(-0.62 \%)\end{array}$ & $\begin{array}{c}9.0 \\
1.7899 \\
(-0.56 \%)\end{array}$ & $\begin{array}{c}1.7918 \\
(-0.46 \%)\end{array}$ \\
\hline 2.4 & $\begin{array}{c}5.0 \\
2.3948 \\
(-0.22 \%)\end{array}$ & $\begin{array}{c}2.0 \\
2.3997 \\
(-0.04 \%)\end{array}$ & $\begin{array}{c}5.0 \\
2.3946 \\
(-0.22 \%)\end{array}$ & $\begin{array}{c}830 \\
2.3941 \\
(-0.25 \%)\end{array}$ & $\begin{array}{c}2.3957 \\
(-0.18 \%)\end{array}$ \\
\hline 2.7 & $\begin{array}{c}9.0 \\
2.6928 \\
(-0.27 \%)\end{array}$ & $\begin{array}{c}6.0 \\
2.7022 \\
(-0.08 \%)\end{array}$ & $\begin{array}{c}7.0 \\
2.6930 \\
(-0.26 \%)\end{array}$ & $\begin{array}{c}10.0 \\
2.6926 \\
(-0.26 \%)\end{array}$ & $\begin{array}{c}2.6952 \\
(-0.18 \%)\end{array}$ \\
\hline
\end{tabular}




\section{SUMMARY AND CONCLUSIONS}

The spatial response of a $40 \times 40 \mathrm{CsI}$ detector array to a Thomson-scattered X-ray source has been characterized using MCNP. It was observed that approximately $80 \%$ of the total energy-ray beam energy will be deposited in the central four detector voxels. The cross-talk contribution in these central voxels was determined to be less than $1 \%$ of the total energy deposition. This means that the energy deposited in this central portion should be proportional to the X-ray source energy.

Due to the pulsed and highly collimated nature of this type of source, a series of attenuator materials were placed in the X-ray beam prior to the detector array and an unfolding algorithm has been demonstrated to calculate the X-ray energy from the bulk CsI response. Using a series of test cases, the algorithm was shown to predict incident X-ray energy to within $2 \%$ for the energy range considered in this work.

Future work in this project will involve the validation of these methods using experimental data obtained at the UNL Diocles laser facility.

\section{ACKNOWLEDGMENT}

This material is based upon work supported by the U.S. Department of Homeland Security under Grant Award Number 2007-DN-077-ER0007-03. The views and conclusions contained in this document are those of the authors and should not be interpreted as necessarily representing the official policies, either expressed or implied, of the U.S. Department of Homeland Security.

\section{REFERENCES}

[1] N. J. Cunningham, S. A. Pozzi, S. D. Clarke, S. Banerjee, R. Vane, J. Beene, D. Shultz, and D. Umstadter (2008). High-Energy Laser Accelerated Electron Beams for Long-Range Interrogation. Transactions of the $20^{\text {th }}$ International Conference on the Application of Accelerators in Research \& Industry, August $10-15$, Fort Worth, TX, USA.

[2] D. Umstadter et al., "Development of a Source of QuasiMonoenergetic MeV-Energy Photons for Detection of Special Nuclear Materials," CP1099, Conference on the Application of Accelerators in Research and Industry, 20th International Conference, edited by F.D. McDaniel and B.L. Doyle (AIP, 2009), p. 606.

[3] S. Banerjee et al., "All-laser-driven, MeV-energy X-ray source for detection of SNM," Conference on Technologies for Homeland Security, 08 (IEEE, 2008) p. 1.

[4] S. Amano, K. Horikawa, K. Ishihaha, S. Miyamoto, T. Hayakaya, T. Shizuma, and T. Mochizuki (2009). Several-MeV X-Ray Generation at New SUBARU by Laser Compton Backscattering. Nucl. Inst. Meth. A 602, pp. $337-341$.

[5] G. F. Knoll (2000). Radiation Detection and Measurement, $3^{\text {rd }}$ ed. John Wiley \& Sons, New York, New York.
[6] X-5 Monte Carlo Team, (2009). "MCNP5 - A General Monte Carlo N-Particle Transport Code", Vol 1 - 3, LAUR-03-1987, LA-CP-03-0245, LA-CP-03-0284.

[7] http://physics.nist.gov/PhysRefData/XrayMassCoef/ cover.html 